\title{
LOS GEDAGTES OOR DIE PLEK VAN LANDBOU IN ONS
}

VOLKSHUISHOUDING.

(Rede gelewer voor die Landbou-afdeling van die S.A. Akademie).

Die bepaling van die plek van landbou in enige volkshuishouding kan van meer as een aspek benader word. Op direkte of indirekte wyse maak dit tot meerdere of mindere mate 'n bydrae tot die kulturele, maatskaplike en ekonomiese lewe van enige volk. Watter aspek in ' $n$ besondere land die meeste benadruk word en dus steeds groter sorg ontvang, openbaar dan ook 
meesal die vernaamste karaktertrekke en veral die lewensfilosofie van so 'n volk.

By ons ten lande kan nogal die neiging bespeur word om soms net één aspek raak te sien en daardeur sake ietwat uit verband te beklemtoon. Sonder enigsins op wetenskaplikheid of selfs in die geringste mate op oorspronklikheid aanspraak te maak, is die bedoeling met hierdie praatjie om met 'n paar los grepe in voëlvlug en met breë lyne die organiese geheel van ons land en volk in perspektief te bring.

Sodanige reoriëntering van die benadering wat die toekoms van die plek van die landbou in ons volkshuishouding betref is myns insiens ' $n$ dringende behoefte, veral nou waar die verdere ewewigtige ontwikkeling van ons land by belangrike kruispaaie gekom het.

Die Afrikaner moes hard stry om die bestaan en om die lewe. $\mathrm{Hy}$ is deel van 'n volk wat naby die bodem, die diere en die plante gelewe het. Die Suid-Afrikaanse bodem en klimaat het op sy beurt ' $n$ besondere en kenmerkende stempel op die boeregemeenskap, wat in ons land ontstaan het, afgedruk. Ons land met sy strawwe en wisselvallige klimaat, met veelvuldige droogtes, siektes en plae, het ons boere van hulle jeug af geleer om te volhard, om aan te hou en moed te hou, sodat hulle 'n kannie-dood gees van optimisme ontwikkel het, wat seker nie maklik in enige ander land geëwenaar kan word nie.

Ons het so pas die Wonder van Afrikaans herdenk. Mens betwyfel of daar meer as net in die verbygaan in gedagte gebring is, die mate waarin die boere van ons land ook ons taal verryk het. Tereg het ten minste één skrywer onlangs daarop gewys hoedat in die wonder van ons taal die lewe van die Afrikaner bewaar word deur al sy ontwikkelingstadia, van die vroeëre pionier en trekker, die jagter, die krygsman, tot die velerlei vertakkinge van sy bedrywighede in die hedendaagse lewe.

Daardie skrywer wys daarop dat ons in die wonder van ons taal die gedagtenis het aan die trekboer met sy ossewa, met die onderdele, al die trekgoed -. dele van die lewe wat nog ryklik in ons spreekwoorde en idiomeskat leef (agteros kom ook in die kraal, vyfde wiel aan die wa, orige jukskei, noustrop/bokerf trek, ens., ens.). Daar is die herinneringe aan die trekpad self, met sy skofte, maar ook met sy uitspanplekke, veldstoeltjie en doringhoutvure. Daar is die konkrete name aan ons berge, riviere en diere gegee, wat getuig het van die fyn opmerkingsgawe. Dit het dan ook dikwels as bakens die plek en rigting bepaal. In ons taal lewe ook ons veld en die diere van die land. Geen wonder dat 'n Engelssprekende skrywer, G. C. Hobson, gesê het:

„I find it extremely difficult to get the right atmosphere in English when dealing with our veld and its animals."

Histories, sowel as sosiologies, is dit waar dat elke volk sy oorspronklike nasionale kultuurbeslag op die platteland gekry het. Sonder om verder in besonderhede te gaan, kan net konstateer word dat veral by ons Afrikaanssprekendes die platteland nog altyd die grondlegger was van sowel ons kultuur as ons volkskarakter. Ons kan dit dus as 'n land en volk nie bekostig dat 
daardie kultuurkrag deur agteruitgang en/of ontvolking van die platteland verlore gaan nie.

Ook op maatskaplike gebied moet daar 'n sterk genoeg kern van blanke boerebevolking op die platteland behoue bly, as 'n bron waaruit die hele bevolking 'n deel van sy geestelike krag kan put. Anders is daar ernstige gevaar dat die staatkundige en kulturele invloed van die platteland nie net verswak nie maar dat dit selfs kan verdwyn. Dink maar aan die gevolge op staatkundige gebied wanneer, as gevolg van die verdwyning van egte boereverteenwoordigers, die behoudende elemente van die platteland hulle politieke invloed in die bepaling van belangrike beleidsrigtings deur die verskillende wetgewende liggame van ons land gaan verloor!!

Maar by ' $n$ studie van die blanke bewoning van die platteland in SuidAfrika is dit veral nodig dat die rassepatroon van ons land as geheel in aanmerking geneem word. Daar is mense, veral ekonome, wat beweer dat dit nie saak maak of meer blankes die platteland verlaat nie. Hulle wys daarop dat in die V.S.A. en ander ontwikkelde Westerse lande maar ongeveer 10 persent van die bevolking en selfs nog minder by die landbou betrokke is. Suiwer uit 'n ekonomiese standpunt, mag so 'n argument korrek wees. Hier by ons mag die landeling egter nie net aan die volk kos en klere of aan die fabrieke hulle nodige grondstowwe verskaf nie. Hulle het ' $n$ besliste bydrae te maak tot die handhawing van 'n blanke beskawing hier by ons ten lande. Indien die stelling aanvaar word dat hier in Suid-Afrika, meer as in enige ander land, dit van die grootste belang is om 'n standvastige bevolking op die platteland te behou, dan word ons, by 'n ontleding van die huidige toestand van sake, ontnugter by die openbarings wat daaruit te voorskyn kom.

Dis algemeen bekend dat die Regering 'n paar jaar gelede, op aandrang van die kerke en georganiseerde landbou, 'n openbare Kommissie aangestel het om verslag uit te bring en aanbevelings te maak oor die vraagstukke van blanke bewoning van die platteland. Die Kommissie het berugtheid verwerf as die B.B.P. Kommissie, as verkorting van Die Blanke Bewoning van die Platteland-Kommissie.

Alhoewel die verslag van die Kommissie reeds 'n paar maande gelede aan die Regering oorhandig is, is die inhoud daarvan ongelukkig nog nie bekend gemaak nie. Sonder om die algemene bevindings en aanbevelings van die Kommissie te openbaar, kan ' $n$ paar statistiese gegewens tog in die verbygaan genoem word. Dit is gegewens wat wel maklik bekombaar is.

Daar word bv. deur die Buro van Sensus en Statistiek beraam dat daar in 1957 slegs nog $18.84 \%$ van ons blanke bevolking op die plase gewoon het teenoor $25.49 \%$ in 1946 , en $34.76 \%$ in 1936.

Ook vanaf 1911 tot 1957 het daar na beraming sowat 620,000 blankes vanaf die platteland na die dorpe en stede verhuis.

Niemand sou wil bepleit dat die totale plattelandse blanke aanwas op die plase moet bly nie. Trouens soiets sou 
'n ramp vir die landbou wees. Uit 'n suiwer ekonomiese standpunt beskou, is dit noodsaaklik dat 'n deel van die plattelandse aanwas na die stede verskuif, omdat die landbou nie aan al daardie mense 'n behoorlike bestaan kan bied nie. Daar is reeds gewys op die besliste staatkundige en sosiale gevare daaraan verbonde indien die pendule te ver sou swaai en die platte land heeltemal van blankes leegloop.

Daar is egter ' $n$ verdere onrusbarende verskynsel, wat in enige oorsig van hierdie aard beklemtoon moet word. Dit blyk naamlik uit die statistieke dat terwyl die getal blankes op die platteland afneem, daar 'n enorme toename is van nie-blankes op ons plase en in ons blanke gebiede.

Die vraag ontstaan al dadelik wat dit gaan help as gepoog word om dic stede en dorpe blank te hou en hulle word omring deur 'n nie-blanke platteland?

Dat die tekens onrusbarend is, blyk onteenseglik uit die feit dat daar vandag 5,400 en meer plase is wat 'n vyftien jaar gelede (1944/45) nog deur blankes bewoon. was. Hulle is sedertdien verlaat en het nou slegs nie-blanke bewoners, alhoewel die eienaars wel nog blankes is. Dic vérreikende implikasie van so 'n toestand van sake, indien dit toegelaat word om ongehinderd verder te ontwikkel, sal wees dat ons land se voedselproduksie binne 'n geslag of twee in dic hande van nie-blankes sal wees. Gaan ons toelaat dat die blanke beskawing van ons land also mettertyd uit sy bakermat, nl. die boereplase, verdryf word?

Vir kulturele, maatskaplike en staat- kundige behoeftes, is dit dus dringend nodig dat daar opgetree word om 'n gesonde bevolkingsverhouding tussen platteland en stad nie alleen te bewerkstellig nie, maar veral dit te probeer behou en indien moontlik te versterk.

Afgesien van dit alles het die platteland nog altyd mense gekweek wat meer behoudend van karakter is, innig verbonde aan die bodem en die natuur; mense wat 'n sterk godsdienssin en 'n eie indiwidualisme kon openbaar. Indien hierdie behoudende element 'n steeds krimpende persentasie van ons bevol king word, kan daardie mooi elemente mettertyd uit ons volkskarakter verdwyn. Kan ons onverskillig staan teen enige sodanige ontwikkeling?!

Laat ons nou die gordyn so effens lig oor die ekonomiese betekenis en inslag van die landbou in ons volkshuishouding.

Dis oorbekend dat die groot rykdomme van die wêreld nie so seer aan daardie lande toeval wat alleen die primêre produksie beoefen nie maar wel aan hulle wat die sekondêre en tersiêre vermoë besit om die grondstowwe na verbruikersgoedere te verwerk.

So behoort dit dus die begeerte en einddoel van elke goeie burger in ons land te wees om mee te werk vir die dag wanneer ook ons land sy regmatige aandcel sal besit in die industriële rykdomme wat uit die verwerking van ons eie grondstowwe te verkry is. Dit alleen kan groter beveiliging en stabilisasie van ons landsekonomie meebring.

Vanaf die blanke volksplanting in 1652 het die landbou ' $n$ oorheersende rol in die geskiedenis sowel as in die ekonomiese lewe van Suid-Afrika 
gespeel. Dit is eers na die ontdekking van diamante en goud, en veral na die Tweede Vryheidsoorlog dat die mynwese, die handel en die nywerhede stadigaan die landbou in die ekonomiese bedrywighede van die land begin verdring het. Maar 'n feit wat dikwels nie besef word nie, is dat die landbou in Suid-Afrika slegs onlangs tot 'n nywerheid van kommersiële belang ontwikkel het. Gaandeweg het die landbou nie alleen die voedselverskaffer van die bevolking geword nie, maar ook al hoe meer die voorsiener van grondstowwe vir ons seliondêre nywerhede.

Dit was veral met die uitbreek van die jongste Wêreldoorlog (1939) dat ons landbou-ontwikkeling 'n nuwe fase ingelui het. Produksiemiddels, soos kunsmis, trekkers en brandstof, het na afloop daarvan vryelik beskikbaar geword en meganisasie het op groot skaal plaasgevind. Daar het algemene verbetering in boerderymetodes gekom.

As gevolg van navorsing en voorligting deur die tegniese personeel van die Departement van Landbou asook tegniese en finansiële hulp onder die Grondbewaringswet het die produksie per eenheid ten opsigte van verskeie landbouprodukte mooi gestyg. Met behulp van die Bemarkingswet is pryse betreklik stabiel gehou. So is die boere aangemoedig om gaandeweg meer te produseer, totdat daar binne 'n betreklik kort tyd 'n hele aantal landbouprodukte vir uitvoer beskikbaar geword het.

Volgens die Departement van Landbou was byna een derde van alle grondstowwe vir ons nywerhede van die plaaslike landboubedryf afkomstig. So moet dan ook die ontwikkeling van ons nywerhede en ons landbou steeds hand aan hand geskied. Hulle moet aanvullend van mekaar beskou word instede van as mededingend met mekaar bejeën te word. Ons nywerhede word in ' $n$ al hoe meer toenemende mate van die landbou afhanklik vir hul grondstowwe. Aan die ander kant verskaf die ontwikkeling van lanbou aan nywerheidsprodukte self 'n soveel beter mark. Goed gesalarieerde nywerheidswerkers op hulle beurt verskaf 'n afsetgebied vir die boer se produkte.

Hoedat die welvaart van ons land se ekonomie sowel as die welvaart van ons bevolking as geheel saamgevleg is met die wel en wee van sekondêre nywerhede blyk uit die volgende persentasies van die bydrae tot die nasionale inkomstes deur die onderskeie sektore van cns volkshuishouding.

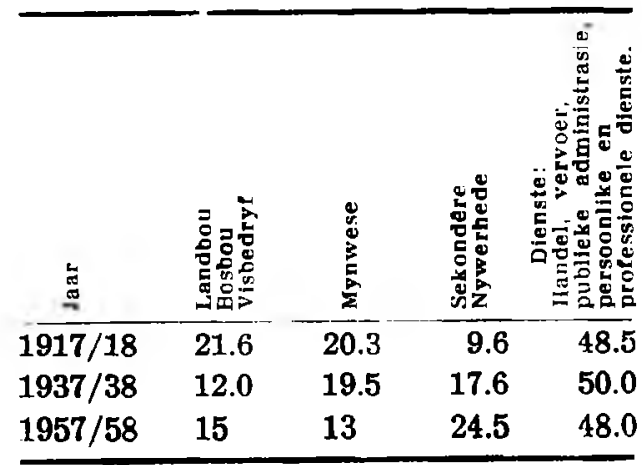

Wat boerderymetodes betref, wil ons boere ongelukkig nog nie heeltemal bewus word van die feit dat Suid-Afrika nog steeds hoofsaaklik 'n pastorale land is en dat sy boerderyhuishouding in die eerste plaas moet berus op die dierefaktor. Die betreklike mate van stabiliteit, wat daar oral in die meer suiwer veedele geheers het teenoor die minder 
gunstige wendings in sommige van ons saaidele en ander vertakkings van die boerdery, het dan ook die B.B.P. Kommissie in besondere mate beïndruk. Dat dit ook in ander lande die geval is, blyk o.a. uit 'n onlangse gesegde van die Eerste Minister van Nieu-Seeland: ..Our grassland fabric is based on the simple symbiotic phenomenon that stock needs grass and grass needs stock."

Die natuurlike weiveld, aangevul deur rusoesskemas, moet die fondament wees waarop ons hele veeboerderystelsels gegrond moet wees. Dit was dan ook bemoedigend vir ons Kommissie om van die Departement van Landbou te verneem dat veldbeheer een van die belangrikste rigtings van hulle navorsingsprogram is, en dat die plan is om op bykans alle veldsoorte, ook deur middel van koöperatiewe proewe met boere, navorsing in verband daarmee te doen.

'n Segsman van die Grootfonteinse Landboukollege het selfs so ver gegaan as om heel kernagtig te verklaar: „Ons moet noodgedwonge ons vorm vir 'n suksesvolle skaapboerdery hersien en ons moet prioriteit skenk aan die langtermyn-welstand van die veld liewer as die onmiddellike welsyn van die skaap".

Daar is dus geen kwessie van dat terwyl die landbou in die ontwikkeling van enige volk ter wêreld 'n heeltemal unieke rol vervul, dit in ons land des te meer die geval behoort te wees. Die Kommissie het dan ook diep onder die indruk gekom hoedat daar in die harte van talle besitlose persone 'n innige verbondenheid met die bodem nog bestaan. Hulle was mense wat werklik in murg en been begeer, en ook die aanleg besit, om selfstandige boere te wees, maar hulle kan nie 'n stukkie grond in hande kry nie en moet dus 'n heenkome elders soek in ander rigtings, waar hulle moeilik aanpas.

Met die oog op allerlei kettery en ideologië wat vandag verkondig word, is dit interessant om daarop te let dat die gedagte van vaste grondbesit deur die indiwidu eers saam met die blanke beskawing na Suid-Afrika gekom het. Die verskynsel was totaal vreemd aan die inboorlinge, wat indertyd van 'n nomadiese, pastorale bestaan afhanklik was, sonder gebondenheid aan enige besondere stuk grond.

As gevolg van verskeie vorme van besettingsprosesse het grondbesit hier by ons 'n heeltemal ander patroon gevolg as in die ouer lande van Europa, waar boere onder die leenheerstelsel veelal slegs arbeiders, deelwerkers of huurders was, met geen vooruitsig op uiteindelike besitreg nie.

Hier by ons het elke boer sy eie stukkie grond verkry en het dit tradisie en drang geword om selfstandig te boer. Geen wonder dan dat ons vandag nog vind dat menige persoon van plattelandse afkoms maar noodgedwonge in die stede woon, nog met groot hunkering terug dink aan die plaaslewe van vervloë dae!! Verskeie gesaghebbende persone het dan ook in hulle formele getuienis die betekenis van grondbesit in die volkslewe beklemtoon. Een getuie het dit kernagtig uitgedruk: ,Sodra 'n grondlose persoon 'n selfstandige grondbesitter word, verander sy uitkyk op die lewe totaal en word hy 'n nuwe mens.... die beste teenvoeter teen 
die Kommunisme is om mense grondbesitters te maak."

So het ons Kommissie diep onder die indruk gekom dat grondbesit geestelike stabiliteit, diepgevestigde wortels van vaderlandsliefde en al die ander behoudende karaktertrekke van ons volk meebring. As die blanke boere van ons land dan 'n bron moet wees waaruit die hele bevolking ' $n$ deel van sy geestelike krag put, dan ontstaan 'n benoude vraag: Wat dan van die toekoms?

Dit is inderdaad 'n vraag wat gedurende die afgelope 70 jaar of so, herhaaldelik onder die soeklig gekom het, as gevolg van die bekommernis van sowel die Staat as die Kerke oor wat die toekoms gaan baar. So was bv. die stigting in 1898 van die Kerklike Arbeidskolonie te Kakamas die uitvloeisel van 'n Konferensie wat in 1893 te Stellenbosch gehou is. Hier het J. X. Merriman, destydse Minister van Landbou van die ou Kaapkolonie, op behendige wyse daarin geslaag om die verantwoordelikheid van die Staat op die skouers van die Kerk af te stoot.

Die toestand van verarming en plaasverlating het na afloop van die Tweede Vryheidsoorlog (1899/1902) ernstige afmetings aangeneem. Daar is toe sowel hier in die Transvaal as in die Vrystaat in 1906 sg. "Indigency Commissions" aangestel om sake te ondersoek en aanbevelings te maak. In 1906 het ook die Kaapse Parlement 'n Gekose Komitee aangestel om die vraagstuk van verarming onder blankes te ondersoek.

In $1922 \mathrm{kry}$ ons die Werkloosheidskommissie wat in sy finale verslag belangrike aanbevelings maak, o.a. dat goedkoop vervoerfasiliteite en beter bemarking vir landbouprodukte ingestel moet word.

Dit was egter die Droogtekommissie van 1923 wat as een van die belangrikste ondersoeke na boerderyaangeleenthede in ons land beskou moet word. Reeds daardie Kommissie het bevind dat die bevolking van die Kaapse Middellande in 'n tydperk van 17 jaar met $12.4 \%$ gedaal het. Die Kommissie het bevind dat dit hoofsaaklik as gevolg van wanpraktyke in die boerdery was dat die veld en grond so erg verniel was dat dit nie meer die hele bevolking kon dra nie.

Teen 1929 egter het die proses van verarming van die blankes so 'n groot omvang aangeneem dat uiteindelik die Carnegie-kommissie benoem is om ' $n$ deeglike ondersoek oor die hele land in te stel. Deel I van hierdie Kommissie se verslag was dan ook getitel: „Plattelandsverarming en plaasverlating". Hierdie verslag was vir ons B.B.P. Kommissie van besondere belang, veral omdat dit meteens vir ons 'n historiese en ekonomiese agtergrond verskaf het.

Afgesien van die grotere ondersoeke was daar ook van tyd tot tyd kleiner amptelike komitees wat die aandag gevestig het op spesifieke aspekte van sake, wat ons nou weer gevra was om te ondersoek. Verder was daar die kerklike kongresse in 1916, 1921, 1923 en 1934, asmede die Volkskongresse van 1939 en 1950. waar dieselfde tema, hoewel soms met 'n variasie van beklem. toning, herhaaldelik onder die soeklig gekom het.

Nogeens moet daaraan herinner word dat, afgesien van die kulturele en 
sosiologiese aspekte, die boerebevolking van alle rasse van ons land geroepe sal wees om $n$ totale bevolking van oor die 30 miljoen siele teen die end van die eeu hier in ons land alleen te voed en te kleed. Ons grondgebruik, boerderymetodes en aantal boere self moet dus steeds met hierdie doelwit voor oë opgebou word. Daartoe moet sonder versuim die nodige voorbereidsels getref word en doelgerigte stappe geneem word

Daar is an die B.B.P.-Kommissie deur getuies meer as ' $n$ honderd afsonderlike oorsake voorgehou, waarom die platteland besig was om leeg te loop. By nadere ondersoek is egter bevind dat die meerderheid van die beweerde oorsake eerder die gevolge as die oorsake was waarom die aandeel van die platteland progressief kleiner word. Terloops kan eers daarop gewys word dat die ontvolking van die platteland nie 'n verskynsel is wat slegs tot die blankes van SuidAfrika beperk is nie. Uit die „United Nations Demographic Yearbooks" blyk dit dat daar oral in oorsese lande so ' $n$ afname van plattelandse bevolking plaasvind. Wat veral uit die beskikbare internasionale gegewens blyk is dat daar 'n duidelike korrelasie bestaan tussen ekonomiese ontwikkeling en verstedeliking van die bevolking. Terselfderiyd word oorsee gevoel dat waar plattelandse ontvolking te ver vorder ander probleme geskep word. Daar word bv. beweer dat die stede in Europa so groot word dat hulle "verstop" raak, ontwikkelingsprobleme oplewer en net massamense skep.

Onlangs is daar in Holland gehou 'n kongres van die Internasionale Bond van Europese Stede en Gemeenskappe. Daar is gekla dat dit alleen fatale gevolge vir die lande as geheel kan hê as die proses aldaar sou voortgaan dat die platteland steeds meer van sy jongere en bekwaamste kragte aan die stede verloor.

Vir lede van die Akademie kan dit van belang wees om spesiaal te let op die taalgroepering van die persone wat steeds meer en meer stadwaarts beweeg. 'n Ontleding van die onderskeie bevolkingsensusse dui daarop dat dit by uitstek Afrikannssprekendes is wat aan die verstedelikingsproses deelneem. Die teenbeeld hiervan is dan ook dat die Afrikaanssprekendes nou besig is om ' $n$ oorwegend stedelike bevolking te word. Hulle maak dan reeds 51 persent van die stedelike bevolking uit, in vergelyking met net 44 persent in 1936. Tot dusver was dit die Engelssprekendes wat by uitstek metropolitaanse bewoners was.

Die B.B.P.-Kommissie is verder in die besonder getref deur die invloed wat die groter of kleiner word van plase uitoefen op die mate van welvaart en stabiliteit waarin die boerebevolking in 'n bepaalde streek verkeer. In die uitwerking van die twee uiterste vorms van grondbesit bestaan daar in verskeie opsigte nogal 'n treffende ooreenkoms.

Dit het geblyk dat daar beslis 'n toename was in die getal kleiner boere en die grond wat hulle besit. In baie gevalle het die plase so klein geword dat dit noodwendig was dat daar 'n aantal boere in sekere streke is wat nie anders kan as om van hulle gronde gedwing te word nie. Daar is geen kwessie van dat onderverdeling in 
sekere dele van die land reeds te ver gegaan het nie en dat in hierdie dele 'n verdere ontvolking beslis ten goede sou wees.

Aan die ander kant is daar dié groep van boere wat te veel grond probeer inpalm het. In getalle het hulle geblyk geringer te wees as wat die algemene opvatting skyn te wees. Terselfdertyd moet erken word dat ook hulle 'n ekonomiese en maatskaplike probleem skep wat aandag vereis. Dit is bereken dat alhoewel die groot grondbesitters tot slegs 3 persent van die blanke boere beperk is, hulle ten minste een derde van die Unie se 102 miljoen morg plaasgrond besit.

Ekonome beweer dat daar in enige bedryf ' $n$ sekere stadium bereik word waar die optimum produksie moontlik is, dit wil sê waar die bedryf sy doeltreffendste peil van maksimum produksie teen die laagste koste per eenheid behaal. Sodra die bedryf dan groter word as daardie optimale stadium, tree verkwistende faktore en bestuursvraagstukke op die voorgrond: en in die landboubedryf, net soos in ander bedrywe, het dit die uitwerking dat die opbrengs per eenheid daal. Die Kommissie het dan ook stawende getuienis ontvang wat bevestig dat namate plase groter word, die inkomste per morg ooreenkomstig daal.

In albei van hierdie verskynsels, nl. van te klein en/of onekonomiese plase of boerdery-eenhede wat te groot is, lê daar dan opgesluit wesenlike gevare wat in die toekoms ernstige aandag sal moet ontvang.

'n Ontleding van die statistieke het ook openbaar dat 73,000 of 78 persent van die 93,000 kommersiële boere in die Unie grondbesitters is en naasteby 20,000 huurders, deelsaaiers en voormanne. Dit was moeilik om met juistheid te beraam hoeveel meer boere as gevolg van allerlei ontwikkelinge 'n goeie bestarn uit die landbou sou kan maak. Dit sou alleen kon geskied indien die besproeiingskemas tot die maksimum uitgebrei kan word en wetenskaplike en tegnologiese boerderymetodes verder kon ontwikkel. So 'n uitbreiding sou in enige geval slegs heel geleidelik kan plaasvind.

Indien die basis van vervanging as één geslag, of dertig jaar, geneem word, dan is bercken dat daar normaalweg jaarliks ongeveer 3,000 jong boere nodig is om die uittredende ouere boere te vervang. Indien verder 'n ruim toelating vir die moontlike toekomstige vermeerdering van boerdery-eenhede gemaak word, kan miskien nog 1,000 persone tot bogenoemde getal toegevoeg word. Daar mag dus in die toekoms sowat 4,000 nuwe boere jaarliks nodig wees om tot die landbou toe te tree. Dit behoort nie moeilik te wees om voldoende voornemende boere te vind om alle vakatures wat daar in die geledere van die kommersiële boere mag ontstaan, aan te vul nie. Maar daar is allerlei vereistes en probleme wat dit nie so maklik maak om sonder meer boer te word nie.

Een van die allerbelangrikste ver eistes vir die vestiging van jong boere, naas liefde vir die bodem en 'n deeglike landbou-opleiding, is die voorsiening van voldoende kapitaal om ' $n$ boerdery op ekonomiese grondslag te begin. Dit het duidelik geblyk dat die dae toe 'n 
jong man met feitlik niks kon begin en mettertyd 'n suksesvolle boerdery opbou, tot die verlede behoort. Die tegniek sowel as die ekonomiese struktuur van die boerdery het sodanig verander dat daar, selfs vir 'n beskeie begin, 'n aansienlike kapitale bedrag vereis word.

In hierdie verband kan dan ook blydskap uitgespreek word dat die Landbankwet onlangs sodanig gewysig is, dat dié Instelling op meer elastiese basis in die behoeftes van ons boerebevolking kan voorsien. Daar het tot dusver 'n besliste gebrek aan 'n gesonde kredietstelsel vir die landboubedryf bestaan.

Terwyl die tegniese dienste wat die Departement van Landbou aan ons land se boere en aan die landbou as geheel lewer veelomvattend is, het die Kommissie tog diep onder die indruk gekom dat vir 'n stabiele en welvarende landboubevolking opleiding 'n allereerste vereiste is. Die bestaande geriewe vir landbou-opleiding moet sodanig uitgebou en uitgebrei word dat die ideaal van 'n opgeleide boer op elke plaas spoedig binne bereik van almal kan kom.

Daar is dus vir een en almal van ons landsburgers baie werk om te doen. Daar is geen sprake van enigeen op sy louere te laat rus, veral nie vir die wetenskaplikes wat by die landbou betrokke is nie. Hulle moet meewerk dat die natuurlike hulpbronne van ons land op planmatige en doelbewuste wyse eksploiteer kan word, ten einde aldrie produksiefaktore van ons land, naamlik die landbou, die mynbou en die nywerheidswese tot 'n gebalanseerde ontplooiing te bring. Ons land kan nie bekostig dat daar in waterdigte kompartemente opgetree word nie maar alleen só dat die een eerder as aanvullend van die ander beskou sal word.

Tog moet die fondamentsteen van al ons ontwikkeling wees die behoud en voortbestaan van die blanke Christelike beskawing in die Unie van Suid-Afrika, wat op sy beurt in die eerste plek gegrondves is in 'n ekonomies onafhanklike, karaktervaste en roepingsbewuste boeregemeenskap.

Dit is die ideaal waarna ons moet streef. Maar daardie ideaal kan alleen verwesenlik word namate ons daarin slaag om ons boeregemeenskap saam te snoer op vaste kulturele, maatskaplike en ekonomiese grondslae. Alleen op so 'n wyse bou ons 'n gesonde plattelandse bevolking op, wat meteens die lewensbelangrike sluitsteen in die organiese geheel van ons volk kan uitmaak.

Daarom is dit bemoedigend om te weet dat die S.A. Akademie vir Wetenskap en Kuns, as die kultuurdraer en dus die kultuurbeskermer, so 'n lewendige Landbouafdeling versorg. Mag hierdie Afdeling in lands- en volksbelang steeds die mees aktiewe en deurtastende van al die Akademie se Afdelings wees.

\section{F. J. DU TOIT.}

Pretoria. 